\title{
Performance of normal hearing preschool children on audiometric ling's six sound test
}

\begin{abstract}
Introduction: Ling's six sound test is a quick and simple test to ascertain access to speech sounds essential for development of optimum listening and speaking skills. However, most of the normative data available for Ling's six sound test is adult based. Therefore, there is a need to develop normative data for subsequent use with children who are receiving early intervention procedures. This study aims at obtaining the awareness and identification thresholds for Ling's six sounds for normal hearing preschool children between 3 to 6 years of age.

Methods: Each of the six sounds of Ling's six sound test namely; |a| |i| |u| |s| |sh| |m| were presented in the sound field through an audiometer to fifty 3 to 6 -year-old children with normal hearing sensitivity in a sound treated room. Each child was explained the task and was conditioned well before the testing. Both awareness and identification thresholds were obtained. The lowest level at which the child responded was noted as the threshold.

Results: The lowest threshold for awareness and identification was obtained for the sound |a| (10.3 dB HL and 15.4 dB HL respectively). whereas the highest threshold was obtained for the sound $|\mathrm{s}|(18.2 \mathrm{~dB}$ HL and $24 \mathrm{~dB}$ HL respectively. A significant difference was seen in thresholds across all the sounds for both awareness and identification.

Conclusions: The differences seen in thresholds across all the sounds for both awareness and identification are due to several higher order factors as well as the acoustic and spectral features of each of the Ling's six sounds.
\end{abstract}

Keywords: Ling's six sounds, awareness, identification, formants
Volume II Issue 5 - 2019

\author{
Shrutika Milind Gaikwad,' 'Vedanti Arvind \\ Patil, ${ }^{2}$ Aparna Nandurkar ${ }^{3}$ \\ 'Sound Steps-An Early Intervention Center, India \\ ${ }^{2} \mathrm{SNEH}$ Rehabilitation Education and Research Center, India \\ ${ }^{3}$ Department of Audiology,AYJNISHD (D), India
}

Correspondence: Aparna Nandurkar, Department of Audiology, Lecturer (Speech and Hearing), AYJNISHD (D), Bandra (E), India, Email aparnanitinnandurkar@gmail.com

Received: October 14, 2019 | Published: October 24, 2019

\section{Introduction}

Intervention of childhood hearing impairment includes fitting and use of hearing aid and/or cochlear implant which is an important milestone of child's habilitation or rehabilitation process. An efficient functioning of these devices ensures the optimal benefit obtained by the child. Several speech perception tests are available to assess this benefit. Most of these tests are word and sentence recognition tests that are fairly time consuming. Therefore, Ling \& Ling, ${ }^{1}$ stated that Daniel Ling's six sound test is a quick and simple test to ascertain access to speech sounds essential for development of optimum listening and speaking skills. It is used routinely by clinicians and by parents and family members for a quick listening check. It is useful to rapidly check whether the device is functioning well or not. Ling's six sound test includes six distinct sounds namely $|\mathrm{a}|,|\mathrm{i}|,|\mathrm{u}|,|\mathrm{s}|,|\mathrm{sh}|$ and $|\mathrm{m}|$. These sounds have different frequency ranges which ultimately cover the entire speech spectrum from low to high frequency.

Many times, it offers an unblemished picture of the child's hearing in terms of the speech spectrum in day to day life, during therapy and after mapping sessions by providing assistance to estimate child's aided speech sound detection, identification and ability of discrimination. It is administered at two levels-awareness and identification. The test is completed using auditory modality to estimate auditory skills and can also be administered using auditory-visual modality to estimate which of the two modalities is predominant. This was also supported by Smiley $\mathrm{F}^{2}$ who used this low tech tool for testing child's communication abilities and also explained its applications throughout the four stages of listening; picking up problems in hearing or hearing amplification systems and not restricted to just detection. Another recent review was done on use of Ling 6 sound test and its applications in Korea and emphasized the importance of its usage not only for the clinicians to assess the hearing device but also for parents on a daily basis as a tool to check the functioning of the device. ${ }^{3}$

In spite of its usage on a day to day basis and its imperative role in the life of young children with hearing impairment, no normative data is available to which thresholds of children with hearing impairment can be compared. In Indian context, no such data is existing till date. Few studies have been conducted attempting to trace the normative thresholds of Ling's six sound test in adults. ${ }^{4}$ Glista D et al., ${ }^{5}$ studied the effectiveness of Ling 6 sound test in measuring pediatric hearing aid outcomes by obtaining unaided and aided Ling 6 thresholds. A CD format was used for the same and reliable thresholds were obtained for 3 to 18 year olds. These results combined with the responses from the audiologists about its use in clinical settings further supported the usefulness and applications of the Ling 6 test. Another study was done by Scollie et al., ${ }^{6}$ to develop and evaluate a calibrated version of the Ling six sounds for evaluation of aided detection thresholds. They found that aided sound field thresholds for adults were influenced by their hearing levels and were better for low-frequency sounds. However, a difference was seen between adults and children. Most of this normative data is for adults but more data is needed with respect to children. Therefore, there is a need to develop normative data for subsequent application to privileged children who are receiving early intervention procedures. 
This study aims at obtaining the awareness and identification thresholds for Ling's six sounds for normal hearing preschool children between 3 to 6 years of age.

\section{Materials and methodology}

Participants: Fifty normal hearing pre-schoolers in the age range of 3-6 years participated in this study. The mean age of the participants was 4.5 years.

Preliminary examination: Brief case history of each child including the prenatal, perinatal and post-natal history was noted down before starting the procedure. The children were also informally screened for any cognitive and linguistic deficits. Otoscopic examination was done using a hand-held Welsh-Allyn otoscope to ensure the absence of any external ear canal blockage, tympanic membrane rupture, and other explicit external ear pathology. A pure tone screening was done at $25 \mathrm{~dB} \mathrm{HL}$ at frequencies from $250 \mathrm{~Hz}$ to $8 \mathrm{KHz}$ in both the ears using GSI 61 audiometer with calibrated ANSI S3.6/ISO 389. ${ }^{7,8}$ Immitance audiometry was also done using GSI 38 immitance audiometer calibrated as per ANSI S3.6/ISO389 to ensure normal middle ear functioning. Children who had no significant medical history, no apparent cognitive linguistic deficits, no external and/or middle ear pathology and who passed audiometric screening at each frequency in both the ears were included in the present study. A written consent was obtained from the parents.

Stimuli used: Ling's six sounds /a/, /i/, /u/,/s/, /sh/, /m/

Procedure: Testing was done in a sound treated room with two room set up with ambient noise levels within permissible limits according to ANSI standards. ${ }^{7,8}$ GSI 61 audiometer calibrated was used for testing. Each child was made to sit comfortably. Two loudspeakers were placed at a distance of 1 foot and $45^{\circ}$ azimuths from the participant. Stimuli were presented through right/left speaker. Each child was conditioned well before audiometric screening. More time was invested for conditioning of children in the age range of 3-4 $1 / 2$ years. After passing the inclusion criteria, each child was explained the task and was conditioned again using Ling's six sounds before presenting a stimulus through audiometer at a comfortable supra-threshold level. Suitable reinforcement was given to the child during conditioning. During actual testing procedure, initial presentation was at suprathreshold level followed by descent in $10 \mathrm{~dB}$ steps and ascent in $5 \mathrm{~dB}$ steps for each of the sound and the threshold was traced.

Mode of response: For assessing the awareness of the sounds, the child was required to indicate if he/she heard the sound whereas for identification the child could either repeat the sound that was heard or else could choose the options given by the second clinician. The lowest level at which the child responded was noted as the threshold and thresholds were noted down for awareness and identification for each of the six sounds.

\section{Results}

Results obtained were analysed separately for Awareness and Identification.

\section{Awareness thresholds}

Descriptive statistics were obtained for the awareness thresholds of 50 participants. Table 1 shows mean awareness threshold in $\mathrm{dB} \mathrm{HL}$, standard deviation (S.D) and variance for all the six sounds.
The following Graph 1 shows the mean awareness thresholds obtained for each of the six sounds. It can be seen from the graph as well as the table that the lowest mean threshold was obtained for $\mid$ a $\mid$ i.e. $10.3 \mathrm{dBHL}$ whereas the highest mean threshold was for $|\mathrm{s}|$ i.e. 18.2 dBHL.

Table I Mean Awareness threshold in $\mathrm{dBHL}$

\begin{tabular}{llll}
\hline Stimuli & $\begin{array}{l}\text { Mean Awareness } \\
\text { Threshold (dBHL) }\end{array}$ & $\begin{array}{l}\text { Standard } \\
\text { Deviation }\end{array}$ & Variance \\
\hline$|\mathrm{a}|$ & 10.3 & 9.225 & $85.1 \mathrm{I}$ \\
$|\mathrm{i}|$ & $\mathrm{II.4}$ & 9.37 & 87.79 \\
$|\mathrm{u}|$ & 10.4 & 8.68 & 75.35 \\
$|\mathrm{~s}|$ & 18.2 & 7.196 & 51.795 \\
$|\mathrm{sh}|$ & 15.7 & 6.15 & 37.76 \\
$|\mathrm{~m}|$ & 14.5 & 7.089 & 50.26 \\
\hline
\end{tabular}

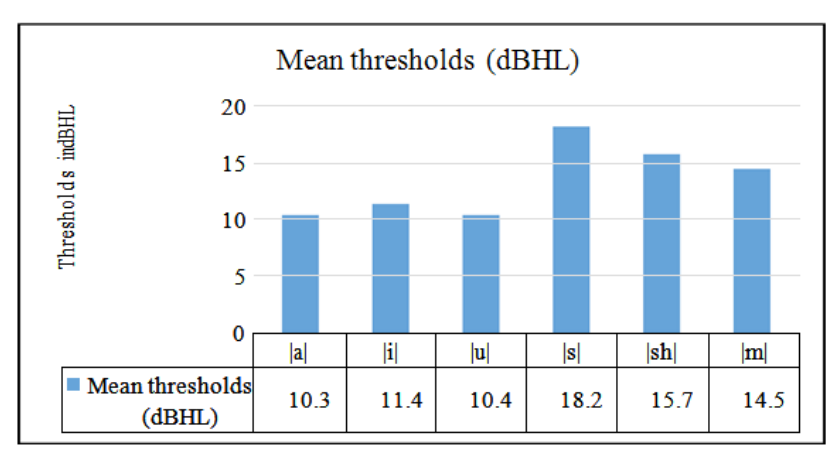

Graph I Mean awareness thresholds for the six sounds.

In order to find out if there is a statistically significant difference between the thresholds obtained across the six sounds, one-way ANOVA was done. Results of one-way ANOVA shown in Table 2 indicate that the difference between the means across 6 groups is statistically significant $(\mathrm{p}=0.00)$.

Table 2 One-way ANOVA results for awareness thresholds

\begin{tabular}{llllll}
\hline Source of & Sum & of & d.f. & Variance $F \quad P$ \\
variation & squares & & & \\
\hline
\end{tabular}

$\begin{array}{llllll}\text { Between } & 2607.41 & 5 & 521.4833 & 8.0621 & 0.0000 \\ \text { groups } & & & & & \end{array}$

$\begin{array}{llll}\text { Within } \quad 19016.83 & 294 \quad 64.6831\end{array}$

groups

Total $\quad 21624.25 \quad 299$


Post hoc analysis done using Turkey HSD test reveals that mean awareness thresholds for the pairs $|\mathrm{a}|-|\mathrm{s}| ;|\mathrm{a}|-|\mathrm{sh}| ;|\mathrm{i}|-|\mathrm{s}| ;|\mathrm{u}|-|\mathbf{s}| ;|\mathrm{u}|-|\mathrm{sh}|$ significantly differ from each other.

\section{Identification thresholds}

Descriptive statistics were obtained for identification thresholds of 50 participants. Table 3 shows mean threshold in dB HL, Standard deviation (S.D) and variance for all the six sounds. The following Graph 2 shows the mean identification thresholds obtained for each of the six sounds.

Table 3 Mean identification thresholds for the six sounds

\begin{tabular}{llll}
\hline Stimuli & $\begin{array}{l}\text { Mean } \\
(\mathbf{d B H L})\end{array}$ & S.D & Variance \\
\hline$|\mathrm{a}|$ & 15.4 & 9.73 & 94.73 \\
$|\mathrm{i}|$ & 19.1 & 8.25 & 68.05 \\
$|\mathrm{u}|$ & 16.8 & 8.96 & 80.36 \\
$|\mathrm{~s}|$ & 24 & 7.07 & 50 \\
$|\mathrm{sh}|$ & 21.6 & 6.42 & 41.27 \\
$|\mathrm{~m}|$ & 21 & 7.62 & 58.16 \\
\hline
\end{tabular}

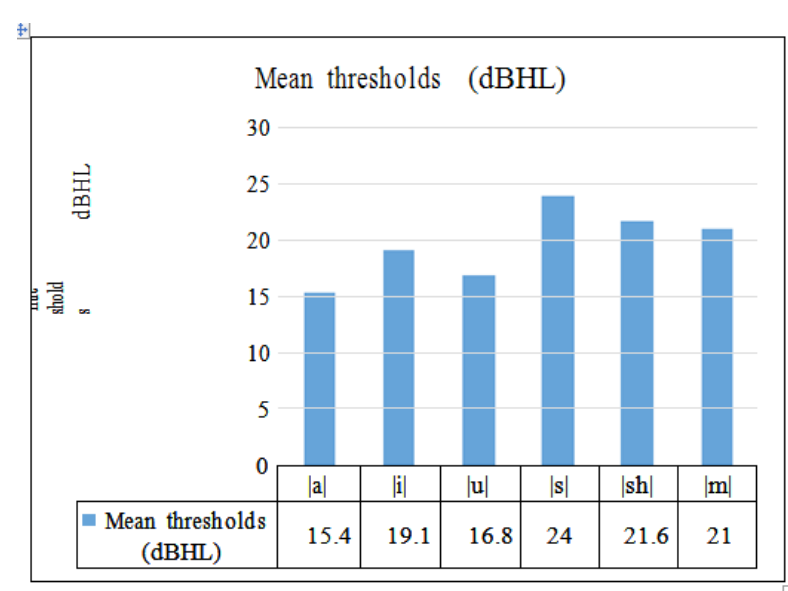

Graph 2 Mean identification thresholds for six sounds.

It can be seen from the graph as well as the table that the lowest mean threshold was obtained for $|\mathrm{a}|$ i.e. $15.4 \mathrm{~dB} \mathrm{HL}$ whereas the highest mean threshold was for $|\mathrm{s}|$ i.e. $24 \mathrm{~dB}$ HL. In order to find out if there is a statistically significant difference between the thresholds obtained across the six sounds, one-way ANOVA was done. Results of oneway ANOVA shown in Table 4 state that the difference between the mean thresholds of the six sounds is statistically significant $(p=0.00)$. Post hoc analysis done using Turkey HSD test reveals that the mean identification thresholds of the pairs $|\mathrm{a}|-|\mathrm{s}| ;|\mathrm{a}|-|\mathrm{sh}| ;|\mathrm{a}|-|\mathrm{m}| ;|\mathrm{i}|-|\mathbf{s}| ;|\mathrm{u}|-|\mathrm{s}|$ $|\mathrm{u}|-|\mathrm{sh}|$ significantly differ from each other.

\section{Comparing means of awareness and identification thresholds for the six sounds}

The following Graph 3 shows comparison of awareness and identification thresholds for each of the six sounds.

The difference in $\mathrm{dB}$ between the mean thresholds for awareness and identification ranges between 5 to $7 \mathrm{~dB}$. In order to find out if there is a statistically significant difference between the thresholds obtained for awareness and identification of each sound, $\mathrm{z}$ test was done. Results reveal that there is a statistically significant difference between the mean thresholds obtained for awareness and identification for each of the sounds $(\mathrm{p}<0.05)$. The following Table 5 shows the results of $z$ test.

Table 4 One-way ANOVA results for identification thresholds

\begin{tabular}{llllll}
\hline $\begin{array}{l}\text { Source } \\
\text { variation }\end{array}$ & $\begin{array}{l}\text { Sum } \\
\text { squares }\end{array}$ & of & d.f. & Variance F & P \\
\hline $\begin{array}{l}\text { Between } \\
\text { groups }\end{array}$ & 2551.75 & 5 & 510.35 & 7.8059 & 0.0000 \\
$\begin{array}{l}\text { Within } \\
\text { groups }\end{array}$ & 19221.85 & 294 & 65.3805 & & \\
Total & 21773.60 & 299 & & & \\
& & & & & \\
\end{tabular}

Table 5 Results for comparison between awareness and identification thresholds

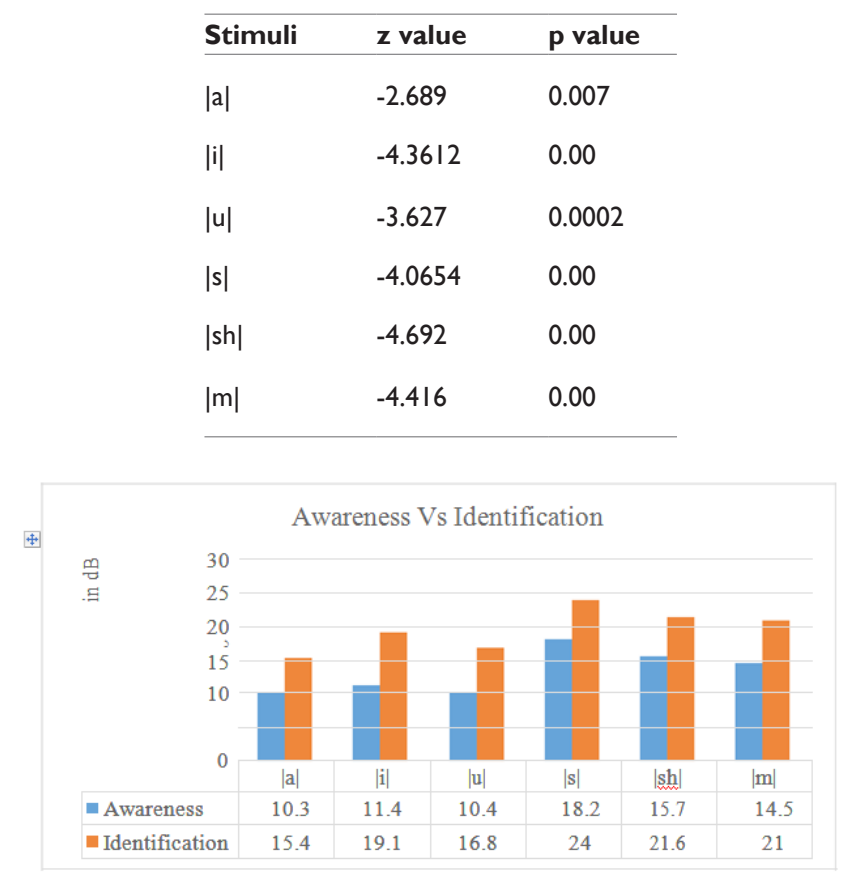

Graph 3 Comparison of awareness and identification thresholds.

\section{Discussion}

Descriptive statistics done to obtain the awareness and identification thresholds state that the lowest awareness and identification threshold was obtained for $|\mathrm{a}|$ which is $10.3 \mathrm{~dB}$ HL and $15.4 \mathrm{~dB}$ HL respectively whereas the highest threshold was obtained for $|\mathrm{s}|$ which is $18.2 \mathrm{~dB}$ $\mathrm{HL}$ and $24 \mathrm{~dB}$ HL respectively

The acoustic features that contribute to the vowel identification are fundamental frequency, formant frequencies (F1 and F2), vowel duration and voicing. $|\mathrm{a}|$ is a low back vowel with a low frequency energy spectrum. It has a high F1 i.e. $710 \mathrm{~Hz}, \mathrm{~F} 2$ at $1100 \mathrm{~Hz}$ and 
F3 at 2540. Therefore, the separation between the F1 and F2 is less thereby making it easier for perception. This also explains why lowest threshold was obtained for /a/. |i| is high front vowel which has F1 at $280 \mathrm{~Hz}, \mathrm{~F} 2$ at $2250 \mathrm{~Hz}$ and F3 at $2890 \mathrm{~Hz}$. Therefore |i| has lower F1 and higher F2 with a lot of separation between the two formants thereby making it relatively difficult to perceive this sound. $|\mathrm{u}|$ is a mid - back vowel with $\mathrm{F} 1$ at $310 \mathrm{~Hz}, \mathrm{~F} 2$ at $870 \mathrm{~Hz}$ and $\mathrm{F} 3$ at $2250 \mathrm{~Hz}$. With a little separation between $\mathrm{F} 1$ and $\mathrm{F} 2,|\mathrm{u}|$ is also easy to perceive. Due to this closeness of $\mathrm{F} 1$ and $\mathrm{F} 2, / \mathrm{a} /$ and $/ \mathrm{u} /$ have relatively lower thresholds in both awareness and identification than other sounds. Nasals like $|\mathrm{m}|$ are produced with a vocal tract constriction and have a lesser energy than vowels. Formant transitions contain the most crucial information. F1 tends to be low $(250-300 \mathrm{~Hz})$ and F2 around $2500 \mathrm{~Hz}$. In between (where vowels have F2) there is little energy. ${ }^{9}$

Hillenbrand et al., ${ }^{10,11}$ stated that awareness is primarily determined by the spectral peak levels whereas identification requires information regarding formant frequencies. $/ \mathrm{a} /, / \mathrm{i} /, / \mathrm{u} / \mathrm{and} / \mathrm{m} /$ have similar peak spectral levels and hence also account for lower awareness thresholds than the rest. On the other hand, acoustic features of consonants are dependent mainly on the formant frequencies and the transitions. Fricatives like $/ \mathrm{s} /$ and $/ \mathrm{sh} /$ contain high frequency information. Analysis of its spectrum shows energy from approximately $2000 \mathrm{~Hz}$, up to and above $8000 \mathrm{~Hz}$. Peaks of energy at 4500 and $7500 \mathrm{~Hz}$. The presence of noise energy characterizes the fricatives that makes it difficult to perceive and therefore highest thresholds for identification was obtained for $/ \mathrm{s} /$.

Furthermore, statistical analysis also stated that there is a statistically significant difference for the awareness and identification thresholds obtained between $|\mathrm{a}|-|\mathbf{s}| ;|\mathrm{a}|-|\mathrm{sh}| ;|\mathrm{i}|-|\mathbf{s}| ;|\mathrm{u}|-|\mathbf{s}| ;|\mathrm{u}|-|\mathbf{s h}| ;|\mathrm{a}|-$ $|\mathrm{m}|$. These differences are attributed to the above stated acoustic and spectral characteristics of these sounds $-/ \mathrm{a} /$ and $/ \mathrm{u} /$ being low frequency vowels are easy to perceive as well as identify when compared to high frequency sounds like /s/ and /sh/ that are characterised by higher concentration of frication noise and formant transitions. This itself makes it difficult to identify $/ \mathrm{s} /$ and $/ \mathrm{sh} /$. The greater separation between F1 and F2 for /i/ results in a slightly higher threshold for /i/ but the frication energy in $/ \mathrm{s} /$ and $/ \mathrm{sh} /$ helps in differentiating the two sounds which is also reflected in the statistical post hoc analysis of both awareness and identification. Therefore, it can be concluded that the differences obtained in post hoc analysis for different pair of sounds are due to their formant frequencies and acoustic features.

Another spectral analysis of the frequency range of Ling six sounds along with three consonants in syllables, i.e., $/ \mathrm{m}(\mathrm{o}) /, / \mathrm{s}(\mathrm{q}) /$, and $/ \mathrm{s}(\mathrm{l}) /$ was done by Aijun Li et al..$^{12}$ Based on the frequency distribution of these sounds, guidelines were stated with inclusion of tones in standard Chinese due to the dialectal differences within the country itself. Despite its simplicity, Ling six sound test is studied globally due to its effectiveness and is modified according to dialectal and phonological variations. This makes the test quite universal.

\section{Comparison of awareness Vs identification thresholds}

Awareness involves detecting the presence or absence of sound whereas identification involves discriminating as well correctly identifying the sound. Though the difference obtained in $\mathrm{dB}$ was only 5 to $7 \mathrm{~dB}$, a statistically significant difference was still seen on $\mathrm{z}$ test. Since the test was administered on pre-schoolers ( 3 to 6 years of age), several higher order factors such as attention, concentration, neuromaturation also affect overall performance on this test. Processing of any auditory stimuli is dependent on the overall arousal state and the ability to attend to the stimulus. Inadequate attention can easily interfere with the perception. Children below 6 years of age tend to have reduced attention and concentration thereby yielding slightly higher overall thresholds. These overall higher levels can be much more appreciated when compared to a study done on adults between 21 and 35 years in which detection thresholds for Ling's six sounds ranged from $0.0 \mathrm{~dB}$ to $21.8 \mathrm{~dB}$ using recorded presentations.

Neuromaturation plays another important role in attending to tasks like identification and discrimination. Neuromaturation takes place at different rates and for several years followin g birth. ${ }^{13}$ Identification is a slightly complex task wherein the child is not just expected to detect the presence or absence of sound but also discriminate and identify the sound correctly thereby giving higher identification thresholds than awareness. At the same time, live voice presentation could also affect these thresholds. Males have an overall higher intensity for all sounds except for $/ \mathrm{m} /$ whereas frequency of speech is lower for all the Ling six sounds than the females leading to intensity and frequency variation that can be attributed to the speech production in males and females and despite these variations, its outcome as a hearing screening tool is not largely affected..$^{14}$ In addition to these factors, the different acoustic features of each of these Ling's six sound affect the identification threshold.

\section{Conclusion}

It can be concluded that the awareness and identification thresholds can be obtained for pre-schoolers though the thresholds tend to be higher due to influence of several higher order factors. Also, acoustic features such as formant frequencies contribute mainly in identification thereby making some sounds easier to identify than others.

Strength: This study attempts to obtain Ling's six thresholds for both awareness and identification for a very young age group.

Limitations: The study was done on a small sample size of 50 children. Also, live voice was used for testing instead of recorded version.

\section{Implications}

It can be used as a preliminary study and can serve as a baseline for future similar studies to be done on children above 6 years of age. It can be used as a tool for comparison with hearing impaired children either using hearing aids or cochlear implants of similar age. A normative data can be developed using a larger sample size of wider age range.

\section{Acknowledgements}

This research was supported by Ali Yavar Jung National Institute for Speech and Hearing Disabilities (Divyangjan). Authors thank this institution for providing the resources and equipment required for this research. The co-operation of the participants and their parents is acknowledged.

\section{Conflicts of interest}

The authors declare that they have no conflict of interest. 


\section{Funding details}

None.

\section{References}

1. Ling D, Ling AP. Aural Habilitation: The foundations of verbal learning. AG Bell Association of Deaf: Washington DC; 1978

2. Smiley DF, Martin PF, Lance DM. Using the Ling 6 sound test everyday. Audiology online. 2004.

3. Park H, Kim J. Comprehension and application of the ling 6 sound test. Audiology and speech research. 2016;12(4):195-203.

4. Tenhaff J, Scollie S. Normative Threshold Levels for a Calibrated, Computer assisted version of the Ling-six sound test. Canadian Acoustics. 2005;33(3):44-45.

5. Glista D, Scollie S, Moodie S et al. T he Ling 6(HL) test: typical pediatric performance data and clinical use evaluation. $J$ Am Acad Audiol. 2014;25(10):1008-1021.

6. Scollie S, Glista D, T enhaaf J. Stimuli and Normative Data for Detection of Ling-6 Sounds in Hearing Level. Am J Audiol. 2012;21(2):232-241.
7. American National Standards Institute. Specifications for Audiometers. (ANSI S3.6 -1989). ANSI: New York; 1998.

8. https://www.iso.org/iso/catalogue

9. Johnson K. Acoustic and Auditory Phonetics. Cambridge, MA: Blackwell; 1997.

10. Hillenbrand J, Getty LA, Clark MJ, et al. Acoustic characteristics of American English vowels. The Journal of the Acoustical Society of America. 1995;97(5):3099-3111.

11. Monahan PJ, Idsardi WJ. Auditory sensitivity to formant ratios: Toward an account of vowel normalisation. Lang Cogn Process. 2010;25(6):808-839.

12. Li A, Zhang H, Sun W. The Frequency Range of "The Ling Six Sounds" in Standard Chinese. Proc Interspeech. 2017; P. 1864-1868.

13. Aoki C, Siekevitz P. Plasticity in brain development. Sci Am. 1988;259(6):56-64.

14. Kilcullen CB. The Ling Six -Sound Test as a hearing screening measure. Towson University Institutional Repository, 2014. 